\title{
LAS SALIDAS ALTERNATIVAS Y LAS SANCIONES NO PRIVATIVAS DE LIBERTAD DE REPARACION DEL DAÑO Y SERVICIOS EN BENEFICIO DE LA COMUNIDAD EN EL SUBSISTEMA DE RESPONSABILIDAD PENAL DE ADOLESCENTES INFRACTORES DE LA LEY PENAL
}

Ana María Morales Peillard

I. Introducción; II. Consagración normativa, planteamiento del problema; III. Justificación dogmática; IV. Efectos jurídicos: a) En relación a los requisitos de procedencia; b) En relación a su contenido y extensión; c) Resolución que se pronuncia sobre la imposición de la medida o sanción y sus consecuencias; d) En relación a la ejecución de las medidas o sanciones; $\boldsymbol{V}$. Consideraciones finales

\section{Introducción}

El día 7 de diciembre de 2005 se publicó la Ley Nº 20.084 que, conforme a lo señalado en su epígrafe, viene en establecer un "sistema de responsabilidad penal de los adolescentes por infracciones a la ley penal”.

Una primera aproximación a la ley deja en evidencia que la misma pretende abarcar bastante más que el reconocimiento de una responsabilidad penal "especial" de los adolescentes, pues además se ocupó de regular el procedimiento aplicable para su juzgamiento y estableció un nuevo catalogo de sanciones no comprendidas orgánicamente en nuestro código punitivo. Sin embargo, es necesario señalar que si bien esta regulación refleja aspiraciones ambiciosas similares a una fusión sustantivo-material de la ley penal aplicable a los adolescentes, ella corresponde más bien a un conjunto de adecuaciones de las normas procesales y penales vigentes, las que han sido morigeradas para efectos de ser aplicadas a sujetos cuya personalidad se encuentra en desarrollo.

Existe una serie de materias reguladas en la Ley $\mathrm{N}^{\circ}$ 20.084, en adelante LRPA, susceptibles de ser revisadas desde una perspectiva crítica, sin embargo el presente artículo se centrará en el tratamiento de las salidas alternativas establecidas en la citada ley y en la regulación de dos casos específicos de sanciones no privativas de la libertad: la reparación del daño y los servicios en beneficio de la comunidad.

\footnotetext{
* Abogado de la Facultad de Derecho de la Universidad de Chile. Coordinadora General, Unidad Coordinadora de la Reforma Procesal Penal, Ministerio de Justicia. Académica de la Facultad de Derecho de la Universidad Arcis. Colaboradora del Centro de Estudios de la Justicia de la Facultad de Derecho de la Universidad de Chile.
} 
Morales - Las salidas alternativas y las sanciones no privativas de libertad...

De este modo, en el presente artículo analizaré, desde una perspectiva normativa y dogmática, la regulación de las salidas alternativas y las sanciones no privativas de libertad de reparación del daño y servicios en beneficio de la comunidad en la LRPA, e intentaré demostrar las consecuencias de su regulación legislativa a la luz de los fines perseguidos con su consagración.

\section{Consagración normativa, planteamiento del problema}

La Ley $\mathrm{N}^{\circ} 20.084$ regula en el párrafo segundo del Título Primero las denominadas "sanciones no privativas de libertad", estableciendo un amplio abanico de sanciones de tal naturaleza dentro de las que podemos encontrar las siguientes: la amonestación, multa, libertad asistida, libertad asistida especial, prohibición de conducir vehículos motorizados, reparación de daño y servicios en beneficio de la comunidad.

El catálogo de sanciones no privativas de libertad es bastante amplio y permite, en principio, entregar respuestas penales diversificadas atendiendo a la gravedad del ilícito y a las realidades socioeconómicas de los imputados adolescentes. Sin perjuicio de lo anterior, es necesario precisar que tales respuestas, salvo la libertad asistida especial y -en principio- la reparación del daño, no resultan ajenas a nuestra legislación penal. Es así como, a modo de ejemplo, en la Ley $\mathrm{N}^{\circ} 20.000$ que sanciona el trafico ilícito de estupefacientes y sustancias psicotrópicas, ya se habían regulado como sanciones principales aplicables a los consumidores, la participación en actividades determinadas a beneficio de la comunidad y la asistencia obligatoria a programas de prevención ${ }^{1}$ y como pena accesoria la suspensión de la licencia para conducir vehiculos motorizados. Por su parte en la Ley $\mathrm{N}^{\circ} 19.327$, sobre prevención y sanción de hechos de violencia en los recintos deportivos, los trabajos voluntarios en beneficios de la comunidad se ofrecen como pena alternativa al cumplimiento de una sanción cuya cuantía legal no sea superior a presidio menor en su grado medio ${ }^{2}$. Por otro lado, es posible encontrar un homólogo, con ciertos matices, a la libertada asistida dentro de la regulación de la Ley Nº18.216 relativa a las medidas alternativas a la pena, particularmente en la figura de la libertad vigilada. Sin embargo, ambas se diferencian en que esta última constituye una alternativa a la pena privativa de la libertad y no propiamente una pena, alterando el régimen de cumplimiento de las sanciones privativa de la libertad.

\footnotetext{
1 Con la misma finalidad, la LRPA regula, como sanción accesoria, la obligación de someter al adolescente a tratamientos de rehabilitación por adicción a las drogas o al alcohol.

2 Sobre la regulación de los servicios en beneficio de la comunidad afirman POLITOFF/ MATUS/ RAMÍREZ, Lecciones de Derecho Penal Chileno, Parte General, Editorial jurídica, Santiago, 2003, pp. 553 que "No es raro, por tanto, que esta clase de sanciones (servicios en beneficio de la comunidad) sean hoy por hoy, tan sólo un objeto de atención académica" considerando que en la mayoría de esos casos sería aplicable la remisión condicional de la pena.
} 
Entrando al análisis particular de las sanciones no privativas de libertad objeto del presente trabajo, encontramos que la sanción de prestación de servicios en beneficio de la comunidad, está regulada en el artículo 11 de la LRPA el que dispone que "la sanción de prestación de servicios en beneficio de la comunidad consiste en la realización de actividades no remuneradas a favor de la colectividad o en beneficio de personas en situación de precariedad". Por su parte, la sanción de reparación del daño se encuentra consagrada en el artículo 10 de la LRPA que dispone que "la reparación del daño consiste en la obligación de resarcir a la víctima el perjuicio causado con la infracción, sea mediante una prestación en dinero, la restitución o reposición de la cosa objeto de la infracción o un servicio no remunerado en su favor". Además, en el inciso segundo se precisa que el cumplimiento de tal sanción no obstará a que la víctima persiga la responsabilidad extracontractual, pero sólo en aquello en que la reparación sea declarada como insuficiente.

Como ya se ha señalado, la consagración normativa, por lo menos respecto de la sanción de servicios de en beneficio de la comunidad, no es ajena a nuestra legislación. Pero tal afirmación no podría, en principio, hacerse extensiva respecto de la sanción de reparación del daño. En efecto, dicha sanción no privativa de libertad es novedosa en cuanto a su configuración propiamente como pena.

Una figura de similares características a la sanción de reparación del daño, encontramos dentro de las consecuencias jurídicas de los acuerdos reparatorios regulados en nuestro Código Procesal Penal (en adelante CPP), eso sí, con una diferencia de trascendencia: los acuerdos reparatorios, prima facie, no corresponden a penas. La misma situación se presentaría respecto de los servicios en beneficios de la comunidad reconducidos como salida alternativa de suspensión condicional del procedimiento a través del artículo 238 letra d) del CPP ("tener o ejercer un trabajo, oficio profesión o empleo, o asistir a algún programa educacional o de capacitación”) o la recientemente incorporada letra h) (“Otra condición que resulte adecuada en consideración con las circunstancias del caso concreto de que se tratare y fuere propuesta, fundadamente por el Ministerio Público") ${ }^{3}$.

Para dilucidar lo planteado en el párrafo anterior, se podría recurrir a una simple explicación: el legislador, con el afán de dejar de lado todo atisbo del denominado "fraude de etiquetas"4 decidió ser claro y no regular conceptualmente como una salida alternativa hipótesis que -en definitiva- no constituyen más que sanciones o claramente penas, evitando así camuflarlas con un ropaje y maquillaje de aspecto resocializador y restaurativo.

\footnotetext{
${ }^{3}$ Letra incorporada al artículo 238 del Código Procesal Penal mediante la dictación de la ley 20.074, de 14 de noviembre de 2005.

4 Para un análisis particular sobre el denominado "fraude de etiquetas" consultar BUSTOS RAMIREZ, "Imputabilidad y edad penal en Justicia Penal y Sociedad." Revista no. 8 Año 6 abril de 1998.
} 
Morales - Las salidas alternativas y las sanciones no privativas de libertad...

El problema al que se enfrenta tal explicación consiste básicamente en que el legislador decidió regular paralelamente dentro de la Ley N²0.084 las salidas alternativas consistentes en la suspensión condicional del procedimiento y los acuerdos reparatorios. En efecto, la primera de dichas salidas alternativas se encuentra expresamente consagrada en el inciso cuarto del artículo 41 que señala "lo dispuesto en este artículo es sin perjuicio de la posibilidad de decretar la suspensión condicional de procedimiento". La segunda de estas salidas, esto es, los acuerdos reparatorios son susceptibles de ser aplicados al procedimiento regulado en la LRPA en virtud de la norma general de reenvío del artículo 27 de la ley, que establece que "La investigación y juzgamiento de la responsabilidad por infracciones a la ley penal por parte de adolescentes se regirá por las disposiciones contenidas en la presente ley y supletoriamente por las normas del Código Procesal Penal".

A este respecto, es necesario precisar, que el tratamiento que brinda la Ley $\mathrm{N}^{\mathrm{o}} 20.084$ a salidas alternativas es totalmente distinto de aquel contemplado en el Proyecto de Ley enviado por el Ejecutivo al Congreso con fecha 2 de agosto de 2002. En efecto, los acuerdos reparatorios se encontraban regulados en forma explícita, eliminándose las limitantes de los incisos segundo y tercero del artículo 241 del CPP 5 . La idea del Ejecutivo en ese sentido, era "establecer una salida alternativa al conflicto jurídico penal, que tratándose de adolescentes, adquiría mayor relevancia" ${ }^{\prime}$. La suspensión condicional del procedimiento, por otro lado, no se encontraba incorporada de forma concreta.

Durante la tramitación legislativa, la regulación de las mismas sufrió varias mutaciones, planteándose incluso, en el caso de los acuerdos reparatorios, incorporar mecanismos de mediación acordes con las tendencias restaurativas comparadas. Asimismo, se alcanzó a establecer como exigencia que tanto el Ministerio Público como la Defensoría contaran con equipos especializados destinados a mediar entre la víctima y el imputado. Sin embargo, en el tercer trámite constitucional, la Comisión Mixta finalmente decidió eliminar la alusión a dicha salida, toda vez que no le resultó satisfactoria la amplitud de su regulación, estimando que la misma podía desnaturalizarse en el evento que se utilizara como un mero mecanismo de compensación económica de quienes disponían de recursos ${ }^{7}$.

\footnotetext{
${ }^{5}$ En consecuencia, se eliminaban las restricciones legales en relación a su ámbito de aplicación, esto es, que los hechos investigados afectaren bienes jurídicos disponibles de carácter patrimonial, consistentes en lesiones menos graves o constituyeren delitos culposos. Además se descartaba la posibilidad de que el juez rechazara su aprobación en base a la existencia de un interés público prevalerte en la continuación de la persecución penal.

6 Vid. Primer informe del Primer Trámite Constitucional, de la Comisión de Constitución, Legislación y Justicia de la Cámara de Diputados, pp.98. Boletín N 3021.

${ }^{7}$ Vid. Informe de la Comisión Mixta en el Tercer Trámite Constitucional, pp.12.
} 
Por otro lado, la suspensión condicional del procedimiento, como se señaló en párrafos anteriores, no se encontraba regulada explícitamente en el proyecto del Ejecutivo; sin embargo paradójicamente, en el segundo trámite constitucional -en una deslumbrante técnica legislativa- se incorporó dentro de la norma que regula la facultad de suspender la imposición de la condena.

Surge entonces la interrogante entorno a la finalidad perseguida por el legislador al regular por un lado la reparación del daño y los servicios en beneficio de la comunidad -vía suspensión condicional del procedimiento- como salida alternativas y, por el otro, consagrar las mismas como sanciones no privativas de libertad ¿Hay acaso justificaciones desde la perspectiva dogmática penal que avalen tal tratamiento diferenciado? ¿Qué ocurre con los fines de la pena en una y otra hipótesis? ¿Se presentarán consecuencias jurídicas distintas en la medida que se opte por una u otra vía? Estas y otras interrogantes intentaré despejar en los próximos capítulos.

\section{Justificación dogmática}

La regulación de las salidas alternativas en los instrumentos procesales penales latinoamericanos, sin duda tiene como antesala las crisis en la administración de la justicia penal y -consecuencialmente- del principio de legalidad como corolario de dicha administración. En este sentido, las salidas alternativas constituyen claras excepciones al principio de legalidad, toda vez que apuntan a reducir la actividad procesal y evitar la aplicación de la respuesta tradicional del derecho penal: la pena ${ }^{8}$.

En este mismo sentido, Maier señala que los mecanismos de resolución alternativa de los conflictos penales son formas no convencionales de solución del conflicto social que generan los hechos ilícitos, que dan paso a la "justicia pactada o consensuada". De esta forma, son modos de reaccionar frente al conflicto social con consecuencias jurídicas alternativas, que desplazan la pena, o cuanto menos no poseen culturalmente ni jurídicamente, tal significado?

El concepto que nos entrega Maier no nos resulta particularmente clarificador para efectos de desentrañar el alcance las salidas alternativas y su diferenciación dogmática respecto de las sanciones no privativas de la libertad, consistentes en la reparación del daño y los servicios en beneficio de la comunidad, de manera que parece oportuno explorar la llamada naturaleza jurídica de las salidas alternativas.

\footnotetext{
8 BOVINO/HURTADO, Principio de Oportunidad y proceso de reforma en América latina. Algunos problemas de politica criminal .Editorial Astrea. Buenos Aires, pp. 7.

9 MAIER, "Mecanismos de simplificación del procedimiento penal", Cuadernos de Doctrina y Jurisprudencia penal, año IV, No8, Editorial Ad-Hoc, Buenos Aires, 1989, pp.
} 
Morales - Las salidas alternativas y las sanciones no privativas de libertad...

Tanto la suspensión condicional del procedimiento como los acuerdos reparatorios pueden ser entendidos, al menos desde una perspectiva teleológica, dentro del concepto de "Justicia restaurativa o restauradora", la que estaría compuesta por una "variedad de prácticas que buscan responder al crimen de un modo más constructivo que las respuestas dadas por el sistema punitivo tradicional, sea el retributivo, sea el rehabilitativo". ${ }^{10}$ Existen otros conceptos más acotados y que tienden a poner énfasis en el aspecto reparador entendiendo la justicia restaurativa como "toda acción orientada primariamente a hacer justicia reparando el daño causado por el delito". ${ }^{11}$

Considerando ambos conceptos, se podría señalar que los mismos se encuentran en relación de género a especie, pues el primero engloba por extensión a todas aquellas soluciones sustitutivas de la pena, inclusive a aquellas que no consten en prestación directa a la víctima, como el trabajo o prestación en servicios de la comunidad o de una institución de bien público, mientras que el segundo representa con su significado restringido (enmienda a favor de la víctima), la forma paradigmática de sustitución de la pena. La ventaja del primer concepto, es que abarca no sólo la reparación material, consistente en la reparación in genere del patrimonio de la víctima, sino que también aquella reparación simbólica en base a soluciones similares como la novación de la obligación por otra que la víctima prefiera o la decisión de una prestación que contemple el interés publico, alternativamente a la obligación a favor de la víctima o conjuntamente con ella, según los casos. ${ }^{12}$

A continuación, tomando como base el concepto amplio de restauración, y entendiendo que las salidas alternativas se encuentran englobadas dentro de dicha construcción, intentaré desentrañar la naturaleza de las mismas. Dada la amplitud del concepto entregado, no es extraño que encontremos distintas versiones sobre la naturaleza jurídica de la restauración y particularmente entender si, cuando hablamos de la misma, lo estamos haciendo en términos sinónimos al de punición.

Para algunos autores, la reparación no tiene un carácter punitivo, pues para ellos, la punición inherentemente se encontraría "teñida de factores retributivos, todos ellos negativos, contraproducentes y disfuncionales". En efecto, señalan que "describir la justicia reparadora con ojos punitivos es ensuciarla" de manera que es

\footnotetext{
${ }^{10}$ Este concepto corresponde a la Propuesta Preliminar de Declaración de los Principios Básicos del uso de programas de justicia reparadora en asuntos criminales, aprobada en el año 2000 en el Congreso de las Naciones Unidas para la prevención del crimen y el tratamiento del delincuente. MIERS y otros, An exploratory Evaluation of Restorative Justice Schemes, Home Office, London, 2001, pp. 9 citado por KEMELMAJER DE CARLUCCI, Justicia Restaurativa, Rubinzal-Culzoni, Buenos Aires, 2004, pp. 109.

11 BAZEMORE/ WALGRAVE citados por LEMLY/RUSSEL, "Implementing Restorative Justice by "Groping Along". A case study in Program Evolutionary Implementation", en The Justice System Journal, vol.23/2, 2002, pp.158.

12 MAIER, "El ingreso de la reparación del daño como Tercera Vía del Derecho Penal Argentino" Derecho Penal Hoy, Editores del Puerto, Buenos Aires, 1996, pp. 32.
} 
necesario "cambiar el vidrio de los lentes (...), abandonar la perspectiva retributiva para adoptar la vista general reparadora" ${ }^{13}$. Asi, para Walgrave ${ }^{14}$, uno de los autores que defiende esta idea, la "pena judicial es una medida impuesta por la justicia criminal basada en la ley para punir o sancionar una conducta que está prohibida por la ley". Desde esa perspectiva, el citado autor postula que la pena produce cuatro requisitos sine qua non, los que, por cierto, no estarían presentes dentro del concepto de justicia restaurativa, a saber: la coercibilidad; el trato duro inflingido; la intención de causar sufrimiento y el vínculo entre la producción de la pena. En este sentido, el autor prefiere asociar la justicia restaurativa más bien a la pena que los padres imponen a los hijos, entendiendo que la misma no corresponde a una cuestión pública, sino más bien privada, en que la sanción trasmitiría un mensaje que quiere enseñar lo que está bien y lo que está mal, concepto que claramente entraría en tensión con la pena impuesta por los jueces los que operan más bien como un canal que pone límites a la venganza ${ }^{15}$.

Otros autores, como Roxin, asocian la noción de justicia restaurativa precisamente al concepto de sanción o punición. El citado autor plantea que la idea de la reparación en el sistema de sanciones jurídico-penales como sustituto de la pena o por lo menos a su aminoración no es extraña al derecho vigente, citando ejemplos de la legislación alemana dentro de los cuales podemos encontrar la suspensión de la pena a prueba o la misma legislación penal juvenil de ese país. Sin embargo, aclara que el escaso significado de la reparación como sanción o sustituto de ella, se minimiza aún más en la práctica, toda vez que la misma se utiliza como "reacción adicional o evasiva", entendiendo en el caso de la sanción la reparación como añadidura a otra sanción y, en el caso de su sustituto, como una clase de respuesta en aquellos casos en que "el delito no es comprobable en un ciento por ciento, pero la sospecha del hecho es tan grande, que no se quiere dejar escapar al imputado totalmente indemne de ello". ${ }^{16}$

Con el objeto de indagar sobre la naturaleza jurídica de la reparación, Roxin plantea que existen tres significados que pueden ser atribuidos a la reparación dentro de los fines la pena. En primer lugar podría ser entendida sencillamente como una composición privada del conflicto, con lo cual la reparación no se integraría al Derecho Penal, pues tendería a lograr una despenalización parcial del mismo. Sin embargo señala, que tal concepción es susceptible de ser criticada toda vez que el marco posible de despenalización estaría muy limitado, siendo a su vez riesgoso retirar al Estado del ámbito de las lesiones más importantes a los

\footnotetext{
${ }^{13}$ KEMELMA JER DE CARLUCCI, Justicia Restaurativa, Rubinzal-Culzoni, Buenos Aires, 2004, pp. 166.

14 WALGRAVE, On restoration and Punishment: Favorable Similarities and Fortunate Differerences, pp. 28 citado por KEMELMAJER DE CARLUCCI, Justicia Restaurativa, Rubinzal-Culzoni, Buenos Aires, 2004, pp. 166.

15 Op. cit. 167.

16 ROXIN, "La reparación en el sistema de los fines de la pena", traducido por MAIER

/CARRANZA en De los delitos y de las víctimas, Ad-Hoc, Buenos Aires, 1992, pp. 4.
} 
Morales - Las salidas alternativas y las sanciones no privativas de libertad...

bienes jurídicos. La segunda posibilidad que sugiere, importa aproximar el Derecho Penal y el Civil, entendiendo la reparación como una tercera clase de pena colocada -para delitos determinados- autómatamente al lado del la pena privativa de libertad y de la multa y susceptible de ser impuesta en su lugar, en casos apropiados. Tal acepción, por cierto, no parece adecuada a juicio de Roxin, partiendo de la base que la escisión entre el Derecho penal y el civil ha sido tan profunda en nuestra tradición jurídica que parecería una utopía pretender invertir la rueda de la historia y combinar por ejemplo la reglas del nullum crimen o el principio in dubio con el derecho civil asimilando, por ejemplo, la condena jurídicocivil al resarcimiento del daño -conforme a su contenido material- como una pena criminal. En seguida, como tercera opción plantea, el reconocer la reparación como un nuevo fin de la pena, que podría alcanzar un significado independiente junto a la retribución, a la prevención general y especial. Sin embargo, el autor desmiente tal interpretación entendiendo que en el Derecho Penal moderno, el fin de la pena sólo puede ser racionalmente el de evitar preventivamente el delito (en cualquiera de sus formas) ${ }^{17}$.

Considerando los argumentos expuestos, Roxin postula construir la reparación, al lado de la pena, como un "tercer carril o vía" del Derecho Penal, esto es, como un instrumento autónomo para la consecución de los fines de la pena, ya sea evitándola o atenuándola. Particular aplicación tendría la reparación en aquellos casos en los cuales, en razón del principio de culpabilidad, no se pueda justificar o sólo se pueda justificar limitadamente el delito, y para efectos de los fines de la pena y a las necesidades de la víctima, aparezca conveniente su aplicación, frente a la posibilidad de una pena sin merma alguna ${ }^{18}$.

En mi entender, la tesis de la reparación como "tercera vía" es la que más se acerca a la construcción jurídica de la reparación y, en particular, de las salidas alternativas, entendiendo las mismas como un instrumento autónomo para la consecución de los fines de la pena, particularmente la prevención especial positiva. En efecto, parece que aunque se quiera "cambiar el lente", la reparación tendrá siempre una consecuencia jurídica-sancionatoria, cuyo objetivo esencial será por lo menos de disuadir al infractor de futuras desviaciones y-eventualmenteresocializarlo.

Es más, si uno observa los principios inspiradores de la LRPA es posible constatar que precisamente la prevención constituye uno de los principios orientadores de su regulación. Así, dentro del mensaje enviado por el Ejecutivo al Congreso se señala explícitamente que "la propuesta contenida en el presente proyecto de ley, constituye una herramienta eficaz para el trabajo preventivo y represivo de la llamada "delincuencia juvenil"1". Además, precisa que "hay que desarrollar un completo sistema judicial y administrativo que asuma, en el ámbito

\footnotetext{
17 Op. cit, pp. 10.

18 Op. cit, pp. 15.

${ }^{19}$ Ver Mensaje 68-347, pp. 11.
} 
de la delincuencia de los adolescentes, las tareas de la prevención del delito, la preservación de la paz social y la seguridad de los ciudadanos" ${ }^{\prime 20}$. En este sentido, se observa que el proyecto asume una posición explícitamente sancionatoria de carácter preventivo, la que, por un lado, se canaliza en la regulación de las salidas alternativas y las sanciones no privativas de libertad y por el otro en el establecimiento de un catalogo especial de sanciones privativas de libertad.

Considerando los argumentos expuestos, podemos concluir, a lo menos preliminarmente, que las salidas alternativas y particularmente aquellas consagradas en la LRPA, constituyen una manifestación de la justicia restaurativa -en su concepción amplia- que vienen en constituir un instrumento autónomo para la consecución de los fines la pena, particularmente la prevención en su dimensión especial positiva, ya sea evitando, atenuando o evitando su aplicación.

En este entendido, no estaríamos frente al concepto tradicional de pena, pero sí frente a una herramienta que busca los mismos objetivos que la pena. Entonces, si el objetivo es el mismo ¿Por qué recurrir a estas herramientas autónomas? Precisamente porque este tipo de instrumentos generalmente no están asociados al concepto tradicional del proceso penal como genuino mecanismo de legitimación "retrospectivo" de la imposición de la pena y por ende de los fines de la misma.

Efectivamente, abandonada la búsqueda de la "verdad material o sustancial" propia de los sistemas inquisitivos, la elaboración de una noción de "verdad procesal" o "verdad formal" ${ }^{21}$ resulta, como señala Horvitz, un objetivo ineludible y fundamental en un modelo garantista del derecho penal. En este sentido, emergen como principios legitimantes de la decisión judicial todas las garantías: el juicio contradictorio, la oralidad, la inmediación, la publicidad de las pruebas que se presentan directamente, contrastadas entre si y con controles cruzados de las partes, satisfaciéndose mejor y más auténticamente el establecimiento de la "verdad procesal" en un proceso de corte acusatorio ${ }^{22}$.

Considerando lo señalado, no es posible desconocer que los mecanismos procesales establecidos por el legislador con el objeto de arribar a decisiones judiciales respecto la aplicación de las salidas alternativas, constituyen un distanciamiento del juicio oral y, en consecuencia, de las garantías procesales legitimantes de la decisión judicial. En efecto, a propósito de la regulación de la

\footnotetext{
20 Op cit, pp. 4.

${ }^{21}$ Para Maier los conceptos de verdad material (o real) y verdad formal no son significados que apunten a conceptos diferentes de lo que entiende por verdad, sino la diferencia estriba más en la formas con las que los diferentes procedimientos judiciales atacan la investigación de la verdad o en los condicionamientos formales para fijar el objeto de la averiguación y para incorporar el material necesario a fin de conocer la verdad histórica. En Derecho Procesal Penal Argentino, I b Fundamentos, Editorial Hammurabi, Buenos Aires, 1989, pp. 562-578.

${ }^{22}$ HORVITZ/ LÓPEZ, Derecho Procesal Penal Chileno, Tomo I, Editorial Jurídica, Santiago,2002, pp. $25-30$.
} 
Morales - Las salidas alternativas y las sanciones no privativas de libertad...

suspensión condicional del procedimiento, Horvitz señala que se le critica el que constituya una "respuesta de carácter sancionatorio impuesta a una persona que no ha sido todavía declarada culpable con todas las garantías del debido proceso" 23 . Sobre el mismo punto, Roxin señala que resulta especialmente peligroso que el cumplimiento de las condiciones e indicaciones, que en teoría es voluntario, en la práctica sea impuesto como una coacción, por cuanto no aceptarlas conlleva la amenaza de la realización del procedimiento penal ${ }^{24}$.

No es posible negar que la regulación de las salidas alternativas corresponde más bien a una opción de política criminal asociada a la crisis del principio de legalidad y la consecuente inserción de la oportunidad (reglada) como una respuesta útil a los problemas actuales del sistema penal. En ese sentido, se señala genéricamente que a lo menos dos son los objetivos principales para los que la aplicación de criterios de oportunidad se pueden convertir en un auxilio eficaz: la descriminalización de hechos punibles, evitando la aplicación del poder penal allí donde otras formas de reacción frente al comportamiento desviado pueden alcanzar mejores resultados o donde resulte innecesaria su aplicación; y la eficiencia del sistema penal en aquellas áreas o para aquellos hechos en los que resulta indispensables su actuación como método de control social, procurando el descongestionamiento de una justicia penal sobresaturada de casos que no permite, precisamente, el tratamiento preferencial de aquellos que deben ser solucionados indiscutiblemente por el sistema, y como intento válido de revertir la desigualdad que, por selección natural, provoca la afirmación rígida del principio de legalidad ${ }^{25}$.

El hecho de que estemos frente una opción político criminal en atención a los fundamentos expresados en el párrafo anterior, importa desatender algunas consideraciones en torno a los fundamentos legitimantes de la decisión judicial. En efecto, entendiendo que la verdad procesal o formal sólo puede ser obtenida a través de un proceso penal con apego a las garantías del sistema contradictorio, encontramos que tal concepto de verdad pasa a ser remplazado por la llamada "verdad consensual" como forma de solución del conflicto y como fundamento legitimante de la decisión judicial, la que a su vez importa una renuncia tácita, por lo menos en el corto plazo, a la aplicación integra de las garantías del debido proceso, en pos de la consecución de otros fines tales como la eficiencia. De esta forma, encontramos un modelo distinto de justicia, fundado en el consenso más que en la verdad histórica ${ }^{26}$.

Existen autores, como Ferrajoli que rechazan cualquier modelo que se base en esquemas "decisionistas" ya sea moralistas, eficientistas o consensualistas ${ }^{27}$. Según el

\footnotetext{
${ }^{23}$ Op. cit., pp. 183.

${ }^{24}$ ROXIN, Derecho Procesal Penal, Editores del Puerto, Buenos Aires, 2000, pp.92.

25 MAIER, Derecho Procesal Penal Argentino, I b Fundamentos, Editorial Hammurabi, Buenos Aires, 1989, pp. 558.

${ }^{26}$ MAIER, Prólogo a De los delitos y de las víctimas, Editorial Ad Hoc, Buenos Aires, 1992, pp.140.

${ }^{27}$ FERRAJOLI, Derecho y razón, Editorial Trota, Madrid, 1995, pp. 67-69.
} 
autor, la elaboración de una noción de "verdad procesal"-entendiendo que la verdad objetiva, cierta, absoluta es la expresión de un ideal inalcanzable- de la verificabilidad y de la verificación procesal resulta ineludible en un modelo garantista del derecho penal y su desconocimiento sólo puede conducir a la arbitrariedad decisionista ${ }^{28}$. Agrega que, en el derecho penal, la única justificación aceptada de las decisiones es la representada por la verdad de sus presupuestos jurídicos y fácticos, entendida la verdad precisamente en el sentido de correspondencia, lo más aproximadamente posible, de la motivación con las normas aplicadas y los hechos juzgados. El citado autor, reconoce que tal sistema cognoscitivo de justificación de las decisiones es bastante más rígido y exigente que los esquemas puramente "decisionistas" que también han sido teorizados y satisfechos, a su juicio en forma tendencial e imperfecta. Agrega que su defensa refleja una opción política a favor de un modelo de derecho penal idóneo para limitar el arbitrio punitivo y para tutelar al máximo grado la libertad de los ciudadanos. Sin embargo, señala que lo que exige en el plano epistemológico y político es precisamente lo que el modelo penal garantista, acogido por las Constituciones modernas, exige normativamente en el plano jurídico: que la legitimidad de las decisiones penales se condicione a la verdad empírica de sus motivaciones $^{29}$.

En mi entender, no es posible desconocer las tendencias político criminales que, como se ha señalado, apuntan fundamentalmente a hacerse cargo de la crisis de los sistemas penales, entregando respuestas útiles frente a la imposibilidad fáctica de perseguir todos los delitos, particularmente a través de mecanismos altamente costosos, como lo es el juicio oral. Sin embargo, estimo que los mecanismos alternativos de resolución de conflictos no deben ser utilizados en forma desmesurada, entendiendo que el juicio oral constituye el mecanismo idóneo para la búsqueda de la verdad procesal, siendo el escenario ideal para el despliegue de las garantías procesales asociadas a sistemas de corte contradictorio, y ese sentido se manifiesta como el indiscutible mecanismo de legitimación "retrospectivo" de la imposición de la pena. Por otro lado, la decisión jurisdiccional en base a un juicio de tales características representa la única posibilidad de emitir un pronunciamiento sobre la culpabilidad basado en la construcción, por lo menos formal, de la verdad. Así en la resolución que se pronuncia sobre las salidas alternativas, el juez no llega a emitir un juicio sobre la culpabilidad y -en tal forma-, se admite la posibilidad de, por ejemplo, revocar una suspensión condicional del procedimiento por incumplimiento de las condiciones establecidas o dejar sin efecto el acuerdo en el evento que el mismo sea incumplido o no se garantice a satisfacción de la víctima su cumplimiento ${ }^{30}$.

\footnotetext{
${ }^{28}$ Op. cit., pp. 147.

29 Op. cit., pp. $68-70$

30 Lo anterior no importa dejar de lado todo elemento valorativo, particularmente desde la perspectiva del fiscal. Así Roxin señala que tomando en cuenta el disvalor del injusto y la magnitud específica de la culpabilidad, este deberá optar por ofrecer o no una suspensión condicional del procedimiento al imputado, la que a su vez se basará en consideraciones de prevención general o
} 
Morales - Las salidas alternativas y las sanciones no privativas de libertad...

Considerando lo antes señalado, y retomando el análisis comparativo de las salidas alternativas y las sanciones no privativas de libertad de los servicios en beneficio de la comunidad y la reparación del daño reguladas en la LRPA, encontramos que -al parecer- estas últimas se condicen en mayor medida con la configuración de un derecho penal garantista, en la medida que las mismas deben ser impuestas a través de una sentencia condenatoria, fruto de un juicio oral y contradictorio, con las garantías que el mismo importa, constituyendo el fundamento de la decisión jurisdiccional y, consecuentemente, de la imposición de dichas penas. En este sentido, es necesario precisar que la LRPA estableció, en forma innovadora, una excepción a las reglas generales respecto del ámbito de aplicación del procedimiento ordinario y los procedimientos especiales, estableciendo que, en el evento que el Ministerio Público solicite una sanción no privativa de libertad -como los servicios en beneficio de la comunidad y la reparación del daño-, el juicio siempre se resolverá en base al procedimiento simplificado, aunque el requerimiento solicite una pena concreta superior a quinientos cuarenta días ${ }^{31}$. En tal sentido, el procedimiento simplificado, a diferencia del abreviado, no significa necesariamente la renuncia a la garantía del juicio oral por parte del imputado ${ }^{32}, \mathrm{y}$ se encuentra rodeado de mayores condiciones de legitimidad para la intervención punitiva estatal y en definitiva para la aplicación de las penas ${ }^{33}$.

En atención a los argumentos expuestos, uno puede arribar a las siguientes conclusiones: dependerá de los operadores en definitiva, el dar solución a la

especial. Vid. ROXIN, "Posición Jurídica y tareas futuras del ministerio público”, El ministerio en el proceso penal, pp.46, citado por HORVITZ op. cit., pp. 143

${ }^{31}$ Inciso segundo, artículo 27 de LRPA.

32 La introducción del procedimiento simplificado dentro de nuestra legislación apunta a la incorporación de mecanismos de celeridad en atención a la ausencia de gravedad de los hechos imputados. Como se señaló, su aplicación no importa necesariamente la renuncia al juicio oral, sin embargo se le critica en la medida que entrega el juzgamiento de los delitos menores al mismo juez que tuvo a su cargo el control de la investigación. Sobre el particular, vid. HORVITZ/LOPEZ, op. cit., pp. 459-462.

${ }^{33}$ Sin perjuicio de lo señalado, los argumentos expuestos tienden a difuminarse, cada vez que se recurra a la modalidad de admisión de responsabilidad por parte del imputado en el procedimiento simplificado, que constituye un homólogo del procedimiento abreviado y, por lo tanto, son susceptibles de serle reproducidos todos los cuestionamientos relativos a dicho procedimiento. En efecto, el procedimiento abreviado se ha entendido como una renuncia al juicio oral y consecuencialmente del cúmulo de garantías que el mismo importa. En tal sentido, diversos autores critican la regulación del procedimiento abreviado y general la institución estadounidense del plea bargaining, en la medida que al través de su aplicación, el fiscal evita tener que probar la culpabilidad del acusado más allá de toda duda razonable y el tribunal es dispensado de establecerla en el juicio, pues se condena exclusivamente en base a confesión. Además, como señala HORVITZ parafraseando a DIAZ CANTON, el procedimiento abreviado estaría "congénitamente viciado" pues toda renuncia o conformidad del imputado precisa libertad total de decisión que por definición se encuentra excluida en la negociación sobre el procedimiento y la pena. Para más literatura sobre el tema, vid. HORVITZ/LOPEZ, op. cit., pp. 510-516 y MAIER/BOVINO, El procedimiento abreviado, Editores del Puerto, Buenos Aires, 2001. 
constante tensión entre garantismo y eficiencia. En tal sentido, encontramos que el fin es el mismo, tanto en las salidas alternativas como en las sanciones no privativas de libertad de reparación del daño y servicios en beneficio de la comunidad, esto es la prevención del delito, cumpliendo por lo menos dos de las funciones preventivo-especiales citadas por Von Liszt, esto es, la función intimidatoria individual y la resocialización (del delincuente en estado corregible) ${ }^{34}$.

La diferencia entre las salidas alternativas y las sanciones no privativas de libertad radica en que las primeras constituyen un instrumento autónomo para la consecución del fin de la pena, esto es, la prevención, mientras que la segunda constituye una forma de respuesta tradicional del derecho penal, a través de la imposición de penas. En ese mismo orden de ideas, las primeras responden a necesidades eficientistas que tienen la ventaja de dar respuestas penales distintas de las tradicionales, particularmente entendiendo que con su aplicación se evita el estatus de "condenado" al que sólo puede se puede arribar mediante la imposición de una sentencia condenatoria.

El problema que presentan las salidas alternativas es que el procedimiento regulado por legislador para su aplicación, lógicamente entra en tensión con las garantías del debido proceso de corte acusatorio y el fin tras la instauración del mismo, esto es, la consecución de la verdad formal o procesal; principios que sí pueden ser observados en un escenario de juicio oral (simplificado), en el que en definitiva, en base a la construcción misma de la verdad formal o procesal y al eventual establecimiento la culpabilidad, pueden ser impuestas las penas no privativas de la libertad de reparación del daño y servicios en beneficio de la comunidad.

\section{Efectos jurídicos}

Habiendo explorado las diferencias en relación al contenido dogmático de las salidas alternativas y las sanciones no privativas de la libertad de reparación del daño y servicios en beneficio de la comunidad, corresponde ahora, entrar al análisis de los efectos jurídicos en torno a la decisión de optar por unas u otras, entendiendo, por cierto, que el fin perseguido en ambas es el mismo:

\section{a) En relación a los requisitos de procedencia}

De acuerdo a lo establecido en el artículo 237 del CPP, para que proceda la suspensión condicional del procedimiento es necesario, en forma copulativa, que la pena en concreto que pudiere imponerse al imputado en el evento de dictarse sentencia condenatoria en su contra no exceda los tres años de privación de libertad y que no haya sido condenado anteriormente, mediante una sentencia

\footnotetext{
${ }^{34}$ Citado por SILVA SANCHEZ, Aproximación al Derecho Penal Contemporáneo, J.M. Bosch Editor, Barcelona, 1992, pp.298 a 310.
} 
Morales - Las salidas alternativas y las sanciones no privativas de libertad...

ejecutoriada, por crimen o simple delito. Por otro lado, la sanción de servicios en beneficio de la comunidad es susceptible de ser aplicada por el juez de garantía, de manera alternativa a un amplio abanico de penas, que se encuentran contenidas en las reglas tercera, cuarta y quinta del artículo 23 de la LRPA, comprendiendo de esta forma un marco penal que abarca desde penas iguales o inferiores a sesenta días hasta tres años. Considerando lo antes señalado, constatamos que el legislador no innovó en esta materia, toda vez que el marco de penas en que unas y otras son susceptibles de ser aplicadas, es similar. En ambos casos, se deberá considerar la rebaja contenida en el artículo 21 de la citada ley para efectos de determinar la pena en concreto, entendiendo que la pena asignada al delito cometido por un adolescente es la inferior en un grado al mínimo de los señalados por la ley para el ilícito correspondiente, regla que a su vez fue suprimida del inciso primero del artículo 72 del Código Penal, para ser reincorporada a la LRPA.

Desde otra perspectiva, conforme a lo contemplado en el inciso segundo del artículo 241 del CPP, los acuerdos reparatorios sólo pueden referirse a bienes jurídicos de carácter patrimonial o a delitos consistentes en lesiones menos graves o culposos. Por otro lado, la sanción de reparación del daño, es susceptible de ser aplicada por el juez tratándose faltas y simples delitos cuya pena no sea superior a quinientos cuarenta días, conforme se desprende de las reglas cuarta y quinta del artículo 23 de LRPA. Como se observa, el legislador entregó un margen mayor de discrecionalidad para la aplicación de la sanción de reparación, en la medida que se ajuste al rango penal establecido en las citadas reglas. Así, si bien la mayor restricción que encontramos en ambas dice relación con que se encuentran referidas a delitos en que el interés afectado es predominantemente privado, el marco de delitos se extiende para efectos de la aplicación de la reparación como sanción no privativa de libertad.

Dentro de los requisitos de procedencia, una diferencia fundamental la encontramos en relación al contenido del consentimiento que debe entregar el infractor. Desde la perspectiva formal, no se observan contrastes considerando que tanto en la suspensión condicional del procedimiento como en la aplicación de la sanción de servicios en beneficio de la comunidad se requiere de la aceptación previa del infractor, y lo mismo ocurre en la regulación de los acuerdos reparatorios y en la reparación del daño, donde además se requiere de la anuencia de la víctima.

Sin embargo, es necesario precisar que el contenido del consentimiento en una u otra hipótesis es diverso. En el caso de las salidas alternativas, la entrega y verificación del consentimiento libre e informado constituye un requisito indispensable de legitimidad para su aplicación, en la medida que el acuerdo del infractor importa una renuncia al derecho al juicio oral ${ }^{35} \mathrm{y}$ a la consecución de la verdad procesal o formal y por ende a todo fundamento retrospectivo para la imposición de una pena. En ese sentido, como ya se ha señalado, las salidas

${ }^{35}$ HORVITZ/LOPEZ, Op. cit. pp.557 
alternativas son herramientas autónomas que claramente tienen contenido sancionatorio punitivo, que son aplicables sin el debido proceso a una persona que debe ser presumida inocente, y en ese contexto el consentimiento debe prestarse necesariamente de manera informada, siendo el rol del juez particularmente intenso en cuanto a precisar el contenido y consecuencias de dicha renuncia y las situaciones procesales que se pueden presentar frente a su incumplimiento.

En el caso de las sanciones no privativas de libertad en comento, la entrega del consentimiento apunta más bien a dar cumplimiento a lo establecido en el artículo 6.2 de la Convención Americana de Derechos Humanos, que proscribe la aplicación de trabajos forzados.

Lo precisado en los párrafos anteriores acarrea consecuencias prácticas de trascendencia. Así por ejemplo, pensemos en un adolescente de 17 años que es formalizado por robo con intimidación (cuya margen penal va desde presidio mayor en su grado mínimo a máximo). A su respecto, concurre la circunstancia modificatoria de la responsabilidad penal del artículo $11 \mathrm{~N}^{\circ} 6$ del Código Penal (irreprochable conducta anterior), y aplicando la rebaja contenida en el artículo 21 de LRPA, el Fiscal eventualmente tendrá dos caminos: pedir la suspensión condicional del procedimiento solicitando al juez la fijación, a modo de ejemplo, de la condición de prestar servicios en beneficio de la comunidad en virtud de letra h) del artículo 238 del CPP, o puede, por otro lado, requerir en su contra en procedimiento simplificado solicitando como máximo una pena de tres años e invitar a la aplicación de alguna de las sanciones contenidas en la regla tercera del artículo 23 de la LRPA, por ejemplo, servicios en beneficio de la comunidad. Intuitivamente uno podría pensar que en definitiva es indiferente el camino por el cual opte el fiscal y que, por cierto, defina el defensor, si las sanciones en ambos casos podrían ser similares. Sin embargo, la diferencia radical que encontramos es que en el primer camino el adolescente prestará su consentimiento para que se le imponga una sanción de carácter punitivo sin que se haya establecido aún su culpabilidad, mientras que en el segundo la misma ya estará establecida y el consentimiento recaerá más bien en el contenido material de la sanción. A lo anterior es necesario agregar que en el evento que el adolescente no preste su consentimiento para la aplicación de una salida alternativa, consecuencialmente se abrirán las expectativas para debatir la inocencia del infractor en el entorno de un juicio oral contradictorio ${ }^{36}$.

\footnotetext{
${ }^{36}$ En el evento que el adolescente no entregue su consentimiento para reparar el daño -como sanción no privativa de la libertad-, el juez podrá, consecuencialmente, aplicar cualquiera de las sanciones contenidas en la regla cuarta o quinta del artículo 23, pudiendo incluso serle aplicada una sanción de internación en régimen semi cerrado, en el evento que la pena concreta aplicable se encuentre en el rango entre sesenta y uno y quinientos cuarenta días. Si el condenado no presta su anuencia para la realización de servicios en beneficio de la comunidad, el juez necesariamente deberá aplicar una pena no privativa de libertad más gravosa, conforme lo establece el inciso tercero del artículo 11 de la LRPA, la que no podrá superar la libertada asistida especial.
} 
Morales - Las salidas alternativas y las sanciones no privativas de libertad...

El escenario planteado es bastante complejo particularmente considerando que trae aparejadas decisiones y consentimientos de sujetos cuya personalidad se encuentran en desarrollo. Sobre el particular, existe un interesante fallo del Tribunal Supremo de Indiana (Lewis v. State, 1972) que a propósito de la renuncia de los derechos de Miranda por parte de un joven de 14 años, señaló que "Este Estado, como todos los demás, ha reconocido el hecho que los jóvenes muchas veces carecen de la capacidad y la responsabilidad para darse cuenta de todas las consecuencias de sus actos. Como resultado de este reconocimiento, los menores son incapaces de ejecutar un contrato vinculante, incapaces de adquirir bienes raíces e incapaces de casarse por su propia voluntad. Sería, ciertamente, inconsistente e injusto, establecer que aquellos a quienes el estado ha estimado incapaces de contraer matrimonio, o comprar bebidas alcohólicas, o incluso donar su propia sangre, debería ser compelido a pararse en el mismo pie que los adultos cuando se les pide una importante renuncia a derechos en el momento más crítico para él y en una atmósfera muy extraña y poco familiar." ${ }^{37}$.

Sobre el particular Estrada ${ }^{38}$ señala, que a partir de la Convención de Derechos del Niño surge con mucha fuerza la noción de los adolescentes como sujetos de derecho, con titularidad de ellos, pero que, atendiendo a que se encuentran en una etapa especial de desarrollo de sus vidas, y en atención a las necesidades de protección del mismo, deben establecerse salvaguardas más exigentes que para los adultos con el objeto de hacer realmente efectivos sus derechos. Asimismo, precisa que, justamente el artículo 4 de la Convención obliga a los Estados Partes a dictar las medidas necesarias para hacer efectivos los derechos garantizados en ella ${ }^{39}$.

En ese sentido, encontramos que consideraciones de tal magnitud, como la renuncia al juicio oral, resultan muchas veces ininteligibles para personas adultas. De esta forma, con mayor intensidad deberá informarse a los adolescentes de su derecho a juicio oral y las consecuencias jurídicas de dicha renuncia. En atención a lo señalado, se torna particularmente relevante el rol del defensor juvenil, el que deberá abogar por la entrega voluntaria y a conciencia del consentimiento del adolescente, pero principalmente deberá evitar decisiones eficientistas que ya resultan riesgosas para el régimen de adultos. Sobre el particular estimo, que las situaciones señaladas sin duda debieran ser reguladas a través de estándares especiales que al efecto determine el Defensor Nacional, con criterios distintos a

\footnotetext{
${ }^{37}$ Fallo citado por ESTRADA en "La renuncia al derecho a guardar silencio por un adolescente en nuestro ordenamiento y en el estadounidense. Comentario a propósito del Fallo In re E. T. C., Juvenile, 141 Vt. 375 (1982), Corte Suprema de Vermont, 24 de junio de 1982”, artículo inédito del autor que examina el derecho a guardar silencio de los adolescentes imputados de infringir la ley penal, en el citado fallo y en la Ley $\mathrm{N}^{\circ} 20.084$.

38 Jefe del Departamento de Menores del Ministerio de Justicia.

${ }^{39}$ Op. cit. pp 10-11
} 
aquellos establecidos mediante Resolución Exenta No395 para el ejercicio de la defensa penal pública de los adultos ${ }^{40}$.

\section{b) En relación a su contenido y extensión}

Sobre el particular, es posible afirmar que la LRPA fue bastante más precisa en determinar el contenido material de las sanciones no privativas de libertad de reparación del daño y servicios en beneficio de la comunidad, a diferencia del CPP. De esta forma, la LRPA precisa que el resarcimiento ${ }^{41}$ puede consistir en una obligación de dar (prestación de dinero), hacer (restitución o reposición de la cosa o objeto de la infracción de servicio remunerado en su favor), a diferencia del artículo 241 del CPP que no entra a regular el contenido del acuerdo, entregando a la jurisprudencia la labor de determinar el contenido de la obligación. Por otro lado, lo mismo puede ser observado respecto de la regulación de los servicios en beneficio de la comunidad -particularmente mediante la inclusión de actividades no remuneradas en beneficio de personas en situación de precariedad-, sin embargo, lo anterior es comprensible en la medida que los servicios en beneficio de la comunidad no fueron regulados orgánicamente dentro de los numerales del artículo 238 del CPP, sino que pueden ser introducidos, como se señaló en páginas anteriores, mediante de la reconducción de las letras d) y h) del citado artículo.

Desde otra perspectiva, particularmente interesante resulta, la regulación de la extensión de los servicios en beneficio de la comunidad en la LRPA, con el objeto de no desvincular socialmente a los adolescentes. El inciso segundo establece que los citados servicios no podrán exceder en caso alguno de cuatro horas diarias y deberá ser compatible con la actividad educacional o laboral que el adolescente realice. Además, señala que la extensión mínima será de 30 horas y la máxima de 120 horas. De esta forma, en el evento que un adolescente sea condenado a prestar el máximo de horas, a razón de cuatro horas diarias, en menos de 30 días, puede haber finalizado el cumplimiento de su condena. Por otro lado, en la misma operación, a razón de una hora al día, obtenemos que máxime estará cumpliendo su condena en 120 días $^{42}$. Lo anterior es importante en la

\footnotetext{
${ }^{40}$ Esto será particularmente necesario en el evento que a futuro la Defensoría Penal Pública decida licitar las causas penales juveniles, particularmente considerando que el juicio oral siempre representará un camino más oneroso, allí donde los servicios licitados están concebidos de tal forma que constituyan un ingreso marginal. Para más literatura sobre el particular, vid. GALLEGUILLOS/MORALES, "Sistema de Licitaciones contractuales de las Defensas Penales Públicas en el Nuevo Proceso Penal Chileno”, Revista de Estudios de la justicia, Nº 4, Santiago, 2004. ${ }^{41}$ Artículo 10 LRPA.

${ }^{42}$ Lógicamente lo anterior variará dependiendo de la cantidad de días de la semana en que se haya comprometido la realización de los servicios. De esta forma, si el adolescente es sancionado con el máximo y sólo se compromete una vez a la semana, a razón de una hora diaria, lógicamente se encontrará aproximadamente tres años en cumplimiento de la sanción, lo que claramente no es una solución razonable desde la perspectiva de la reinserción social y la eventual eliminación de los antecedentes prontuariales.
} 
Morales - Las salidas alternativas y las sanciones no privativas de libertad...

medida que contrasta con la extensión considerada en el inciso sexto del artículo 237 del CPP, que establece que las condiciones que establezca el juez de garantía no podrán ser inferiores a un año, ni superiores a tres.

\section{c) Resolución que se pronuncia sobre la imposición de la medida o sanción y sus consecuencias}

La resolución que se pronuncia sobre la procedencia de salidas alternativas constituye un equivalente jurisdiccional en la medida que la ley le reconoce la aptitud de solucionar conflictos entre partes, sin necesidad de recurrir a una sentencia. Desde otra perspectiva, la resolución que se pronuncia sobre la procedencia de las sanciones no privativas de la libertad en análisis, constituye propiamente una sentencia definitiva, en la medida que pone fin a la instancia resolviendo la cuestión o asunto que ha sido objeto del juicio.

Esta distinción no es baladí, en la medida que las consecuencias jurídicas en relación al infractor son bastantes disímiles. Como ya se señaló anteriormente, una de las diferencias fundamentales entre optar por uno y otro camino, lo encontramos en relación al "estatus" del infractor. Así, tratándose de los adolescentes a los cuales se les ha impuesto una suspensión condicional del procedimiento o un acuerdo reparatorio, estos mantienen el estatus de "imputado", mientras que los adolescentes que son sujetos a algunas de las sanciones no privativas de la libertad en análisis, consecuencialmente obtienen la calidad de "condenado". Esto no es sólo una cuestión semántica acorde con la "voz" imputado utilizada en los artículos 237 y siguientes del CPP. En efecto, la principal consecuencia se produce en relación a la inscripción en el registro general de condenas, regulado en el Decreto Ley No645 de 1925. Según lo dispuesto en el artículo tercero del Decreto Supremo Nº4 de 1960 sobre Prontuarios Penales y Certificados de Antecedentes, se debe filiar a las personas condenadas por crímenes, simples delitos y cuasidelitos. Tratándose de condenados por faltas, se les filiará y abrirá prontuario cuando sean condenados por tercera vez, salvo casos excepcionales establecidos por el mismo legislador.

Pensemos nuevamente en la situación del adolescente de 17 años, formalizado por robo con intimidación, respecto del cual concurre la circunstancia modificatoria de la responsabilidad penal del artículo $11 \mathrm{~N}^{\circ} 6$ del Código Penal. Aplicando la rebaja contenida en el artículo 21 de LRPA, el Fiscal tendrá dos caminos: pedir la suspensión condicional del procedimiento -en el evento que el imputado preste su anuencia-, solicitando al juez la fijación, a modo de ejemplo, de la condición de prestar servicios en beneficio de la comunidad en virtud de letra $\mathrm{h}$ ) del artículo 238 del CPP, o puede, por otro lado, requerir en su contra en procedimiento simplificado solicitando como máximo una pena de tres años e invitar a la aplicación de alguna de las sanciones contenidas en la regla tercera del artículo 23 de la LRPA, por ejemplo, servicios en beneficio de la comunidad. Esta decisión que parece sencilla, va a generar consecuencias jurídicas de importancia en la vida del adolescente. Así, en la primera de las hipótesis, una vez cumplida la 
condición, a lo sumo quedará registrado en el registro que al efecto lleva el Ministerio Público de acuerdo al artículo 246 del CPP y será relevante en la medida que desee optar nuevamente a una salida alternativa. Mientras que en el segundo caso, una vez que se encuentre ejecutoriada la sentencia, el adolescente pasará a ser filiado y prontuariado en el registro de general de condenas de acuerdo a lo dispuesto en el Decreto Supremo N64.

Sin perjuicio de lo señalado, es necesario mencionar que la LRPA introdujo algunas reformas en la materia, toda vez que mediante una modificación al Decreto Ley $\mathrm{N}^{\circ} 645$ se agregó un inciso final al artículo segundo, el que establece que "Los antecedentes relativos a procesos o condenas de menores de edad sólo podrán ser consignados en los certificados que se emitan para ingresar a las Fuerzas Armadas, Carabineros de Chile, Gendarmería de Chile y a la policía de Investigaciones o para los fines establecidos en el inciso primero del presente artículo" (deber del Servicio de Registro Civil e Identificación de comunicar al Ministerio Público, a los tribunales con competencia criminal o a los juzgados de policía local, en su caso, los datos que soliciten para comprobar la reincidencia de los imputados). Si bien la citada reforma apunta a facilitar la resocialización de los adolescentes y no perjudicarlos en su vida laboral futura, hubiera sido deseable que la modificación fuera más profunda, por ejemplo sustrayendo de la obligación de registro a todas aquellas condenas que impusieran sanciones no privativas de la libertad y que al igual que otros casos del derecho comparado europeo, sean eliminados los antecedentes penales una vez cumplida la mayoría de edad.

\section{d) En relación a la ejecución de las medidas o sanciones}

La obligación de velar por el cumplimiento de las salidas alternativas se encuentra entregada al Ministerio Público, el que, a su vez, debe comunicar al juez de garantía cualquier inobservancia grave de las obligaciones impuestas. En este sentido, la regulación en el CPP de la fase de ejecución de estas medidas es bastante sencilla. Así, tratándose de la suspensión condicional del procedimiento, el CPP contempla sólo dos hipótesis en relación a la etapa de cumplimiento, esto es, la posibilidad de modificar las condiciones impuestas y la posibilidad de revocar la suspensión decretada cuando el imputado incumpliere injustificada, grave y reiteradamente las condiciones impuestas o fuere objeto de una nueva formalización por hechos distintos. Las consecuencias asociadas al incumplimiento de las condiciones son claramente perniciosas, en la medida que el adolescente que hubiere sido objeto de la revocación puede arriesgar la imposición de sanciones privativas de la libertad y la aplicación de nuevas sanciones en el evento que hubiere sido objeto de una nueva formalización de la investigación por otros ilícitos. Por otro lado, el CPP opta por un camino muy distinto en el evento que el adolescente no cumpla con las obligaciones impuestas mediante un acuerdo reparatorio, remitiéndose a las normas del Código de Procedimiento Civil relativas al cumplimiento incidental del fallo. 
Morales - Las salidas alternativas y las sanciones no privativas de libertad...

Un tratamiento muy distinto encontramos en relación a la fase de ejecución de las sanciones no privativas de la libertad de reparación del daño y servicios en beneficio de la comunidad. En primer lugar, al adolescente que se impusiere una medida de tal naturaleza, le asiste un amplio catálogo de derechos y garantías asociadas a la ejecución de las sanciones, establecidas en el párrafo segundo de la LRPA que, si bien se asemejan al régimen general de garantías de todos los imputados establecido en el párrafo cuarto del CPP -en cuanto al contenido de los derechos de información y a la defensa técnica-, regulan un nuevo sustrato de información bastante más detallada, que le deberá ser entregada al adolescente, respecto a los programas de los cuales será usuario, junto con el establecimiento de un régimen de reclamación de carácter genérico ante cualquier autoridad competente de acuerdo a la naturaleza de petición. Lógicamente, la idea tras su consagración apunta a entregar las herramientas necesarias para la protección integra de los derechos y garantías que los instrumentos internacionales, y la propia ley, entregan a los adolescentes, de tal forma que no parecería apropiada su aplicación rígida sólo al espectro de sanciones.

En segundo lugar, particularmente interesante resulta la regulación que la LRPA efectúa en relación al quebrantamiento de las sanciones, ya que la citada ley en su artículo 52 establece un mecanismo de correlación entre la sanción quebrantada y la sanción que, consecuencialmente, deberá ser impuesta en virtud del quebrantamiento. En el caso particular del quebrantamiento de las sanciones de reparación del daño y servicios en beneficio de la comunidad, la ley dispone que deberá aplicarse en forma sustitutiva la libertada asistida, en cualquiera de sus formas, por un período de hasta tres meses.

Por otro lado, no es posible dejar de mencionar ciertas innovaciones introducidas por la LRPA en relación a la posibilidad de sustituir, remitir y suspender la condena, junto con la posibilidad de combinar sanciones, instituciones que, por cierto, no son extensibles a las salidas alternativas.

De acuerdo al artículo 53 de la LRPA, la sustitución de la condena consiste en el reemplazo de la sanción impuesta por otra menos gravosa, en tanto ello aparezca más favorable para la integración social del infractor y se hubiere iniciado su cumplimiento ${ }^{43}$. De esta forma, la sanción de reparación del daño, cuando hubiere sido aplicada en virtud de la regla cuarta del artículo 23 (cuando la sanción se ubica entre los sesenta y uno y los quinientos cuarenta días) podría ser sustituida por alguna de las sanciones contenidas en la regla quinta del citado artículo, esto

\footnotetext{
${ }^{43}$ Una institución similar encontramos dentro de la suspensión condicional del procedimiento, en la medida que la misma permite al juez, conforme al inciso segundo del artículo 238 del CPP, modificar una o más condiciones impuestas remitiéndose al catálogo de condiciones que el mismo artículo precisa. En este sentido la regla de modificación del CPP es más genérica, apuntando más bien a evitar un incumplimiento por parte del infractor, y no precisamente el resultarle menos lesiva.
} 
es, servicios en beneficio de la comunidad, multa o amonestación. Si la misma sanción se hubiese aplicado en virtud de la regla quinta, correspondería su sustitución por multa o amonestación. Por otro lado, dependiendo de la regla en virtud de la cual se impusiere la sanción de servicios en beneficio de la comunidad, la misma podrá ser eventualmente sustituida por una sanción de internación en régimen semicerrado, libertad asistida en cualquiera de sus formas, reparación del daño, multa, amonestación. En tal sentido, encontramos que el legislador no estableció un parámetro de sustitución, por ejemplo, de acuerdo a la extensión de la sanción, de manera de entregarles cierta discrecionalidad a los jueces para determinar cuando se entiende que la pena es "menos gravosa", teniendo en cuenta lógicamente el criterio de integración social del infractor. Así, a todas luces no aparece como menos gravosa la sustitución de los servicios en beneficio de la comunidad por la sanción de internación en régimen semicerrado, pero esta es una hipótesis que, por cierto, permite la ley, pero que en definitiva corresponderá a los jueces determinar su ámbito de aplicación, sin perjuicio de que su solo incumplimiento no obliga a modificar la sanción originalmente impuesta. Finalmente, sobre la institución en comento, es necesario mencionar que el legislador reguló la posibilidad de condicionar la sustitución de la pena, de manera que en el evento que la sanción sustitutiva sea incumplida podrá ser retomada la sanción originalmente impuesta. Eso si, de acuerdo al artículo 54 de LRPA, tal posibilidad sólo se contempla cuando la sanción original es de naturaleza privativa de la libertad, de manera que no procede respecto de las sanciones en análisis.

Como se señaló en el párrafo anterior, la LRPA también reguló la posibilidad de remitir el cumplimiento del saldo de condena, cuando existan antecedentes calificados que permitan considerar que se ha dado cumplimiento a los objetivos pretendidos con su imposición. Lógicamente, esta disposición tiene plena aplicación tratándose de los servicios en beneficio de la comunidad, pero al parecer su ámbito de aplicación se difumina tratándose de la reparación del daño, pues en principio no es susceptible de ser remitida la obligación de dar o hacer algo a favor de la víctima, salvo que la misma consienta en que por ejemplo no se le entregue la prestación comprometida, o no se le restituya o reponga la cosa objeto de la infracción, lo que parece del todo ilógico.

La LRPA al igual que el CPP contempla la posibilidad de suspender la imposición de la condena en ciertas hipótesis. En efecto, el artículo 41 de la citada ley faculta al juez para suspender la pena y sus efectos por un plazo de seis meses, cuando el infractor arriesgare sanciones privativas o restrictivas de la libertad iguales o inferiores a los quinientos cuarenta días, pero concurrieren antecedentes favorables que hicieren desaconsejable su imposición. En este entendido, en vez de aplicar una sanción restrictiva de la libertad tales como la reparación del daño o los servicios en beneficio de la comunidad, conforme a las reglas cuarta y quinta dependiendo de la pena en concreto- el juez podrá optar por suspender su aplicación por seis meses, y transcurrido el plazo sin un nuevo requerimiento o formalización, se dejará sin efecto la sentencia, y en su reemplazo se decretará el sobreseimiento definitivo. Sobre el particular, no es posible desconocer que la 
Morales - Las salidas alternativas y las sanciones no privativas de libertad...

aplicación de la mencionada institución dejará prácticamente en desuso las sanciones contenidas en la regla cuarta y quinta del artículo 23 de LRPA, particularmente tratándose de primerizos. En efecto, como es conocido, una de las razones que motivó la modificación del artículo 398 del CPP -homólogo del citado artículo- a través de la Ley $\mathrm{N}^{0}$ 20.074, fue precisamente la aplicación in extenso por parte de los jueces de garantía tratándose de delitos cuya pena en concreto fuera inferior a presidio menor en su grado mínimo, razón por la cual se decidió restringir la aplicación de la suspensión sólo a las faltas penales. Por otro lado, es posible afirmar que la citada modificación no es extensible al sistema adolescente, en la medida que LRPA constituye un subsistema especial dentro de la orgánica procesal penal y su publicación es de fecha posterior a la citada modificación. Tampoco es posible dejar de mencionar que la suspensión condicional del procedimiento se encuentra regulada en la LRPA precisamente con ocasión de la institución en comento, como si fuera posible en razón de un mismo procedimiento suspenderlo condicionalmente y a la vez suspender la imposición de la condena. Lo anterior es únicamente posible tratándose de pluralidad de imputados, y a mi juicio no deja más que entrever la deficiente técnica legislativa de la ley, que entremezcla conceptos en razón de su similitud semántica.

El artículo 25 de la LRPA permite combinar las sanciones establecidas en la regla tercera y cuarta del artículo 23 (internación en régimen semicerrado, libertad asistida en cualquiera de sus formas, prestación en servicios de la comunidad y reparación del daño), cuando ello permita el mejor cumplimiento de los objetivos citados en el artículo 20 de la ley -particularmente la plena integración social- y siempre que la naturaleza de las sanciones permita su cumplimiento simultaneo. Considerando lo anterior, es perfectamente posible que se combinen las sanciones de reparación del daño y servicios en beneficio de la comunidad, particularmente en relación a delitos con víctima conocida en que parezca importante, a criterio del juez, no sólo la indemnidad de la misma, sino que también el establecer la responsabilización del adolescente frente a la comunidad en que el mismo habita.

Finalmente, en relación a la ejecución de las salidas alternativas y las sanciones de reparación del daño y servicios en beneficio de la comunidad, hay dos situaciones -fuera de las ya mencionadas- que las hacen diferenciarse: rol del juez de garantía e institución encargada de velar por el cumplimiento de las medidas o sanciones.

Sobre el primer punto, encontramos que el rol del juez de garantía es bastante más intenso tratándose de las sanciones de no privativas de la libertad en comento. En efecto, la LRPA se preocupó de establecer claramente el rol de ejecución que le compete al juez de garantía en cuanto a la verificación de la legalidad de la ejecución, resolver sobre violaciones de la misma, quebrantamientos y solicitudes de revisión de las sanciones originalmente impuestas. En este sentido, el rol de juez en la LRPA es bastante más activo en la fase de ejecución, que el juez de garantía del sistema de adultos, toda vez que le permite intervenir modificando la extensión o la naturaleza de la pena en la medida que sea aconsejable para el 
correcto desarrollo del adolescente. Por otro lado, la citada ley también innovó en relación a la competencia del juez para efectos del control de la ejecución, generando una regla de excepción respecto de aquella contenida en el Código Orgánico de Tribunales $^{44}$, de manera que con la LRPA se encontrará predeterminada por el lugar en que la sanción debe cumplirse. De esta forma, encontramos que eventualmente el juez encargado de velar por el cumplimiento será distinto, por ejemplo, si los servicios en beneficio de la comunidad son impuestos en virtud de una salida alternativa que si son fruto de una sentencia condenatoria.

Sobre el segundo punto, esto es la institución encargada de velar por cumplimiento, encontramos que el artículo 42 de la LRPA entrega al Servicio Nacional de Menores la administración de las medidas no privativas de la libertad, debiendo dicha institución asegurar la existencia, en las distintas regiones del país, de los programas necesarios para la ejecución y control de la medidas a que se refiere la ley, las que serán ejecutadas por los colaboradores acreditados que hayan celebrado convenios respectivos con dicha institución. Sobre el particular, no hay ninguna razón para excluir la ejecución de las salidas alternativas de la administración del SENAME y, es más, resulta altamente deseable que se incluyan programas para su cumplimiento, de manera de liberar al Ministerio Público de la obligación de celebrar convenios de colaboración, considerando particularmente la escasa importancia práctica que la misma institución ha atribuido al desarrollo de los planes piloto de reparación y mediación del SENAME ${ }^{45}$.

\section{Consideraciones finales}

1.- Ha quedado establecido en el presente trabajo, que tanto las salidas alternativas como las sanciones no privativas de la libertad de reparación del daño y servicios en beneficio de la comunidad responden, desde la perspectiva racional, a los mismos fines, esto es, evitar preventivamente el delito, particularmente a través de su dimensión especial positiva. Sin embargo, la vía formal de consecución de dicho fin, es distinta en uno u otro caso, y también lo son las consecuencias jurídicas que las mismas producen. De esta forma, el procedimiento asociado a las primeras, responde más bien a criterios de carácter eficientistas que en definitiva son elevados frente al cúmulo de garantías que importa el juicio oral, pero que tienen la ventaja de descongestionar el sistema respecto de delitos de menor lesividad social. En el caso de las segundas, la vía formal suele ser más onerosa, pero tiene la ventaja de tener asociado el escenario ideal de despliegue de un verdadero

\footnotetext{
${ }^{44}$ Artículo 14 letra f) del Código Orgánico de Tribunales.

45 Sobre el particular, vid. CENTRO DE ESTUDIOS DE LA JUSTICIA, "Informe final del proyecto del Servicio Nacional de Menores: Seguimiento y validación de los proyectos de la reparación a la víctima y servicios en beneficio de la comunidad", Revista de Estudios de la Justicia, $N^{\circ}$ 5, Santiago, 2005, pp. 225-243.
} 
Morales - Las salidas alternativas y las sanciones no privativas de libertad...

contradictorio, la búsqueda de la verdad procesal o formal y en definitiva del mecanismo de legitimación retrospectivo para la aplicación de sanciones de carácter penal.

2.- Desde otra perspectiva, es posible reprochar al mecanismo de las salidas alternativas el constituir respuestas de carácter sancionatorio, que son aplicables a infractores cuya culpabilidad aun no se ha determinado, y que eventualmente utilizando la vía del procedimiento simplificado, podrían abogar incluso por su inocencia. A lo anterior, es necesario agregar las consecuencias en relación al consentimiento que debe prestar el infractor para efectos de la aplicación de salidas alternativas y las sanciones no privativas de libertad en comento, así en el caso de las primeras, el contenido del mismo dice relación propiamente con la renuncia al juicio oral y las garantías que el mismo importa. En las segundas, su voluntariedad dice relación con la posibilidad de ejercer las labores que se imponen como sanción. Tal diferencia suele ser bastante incomprendida en el régimen de adultos, de tal manera que es posible vaticinar aun mayores dificultades de comprensión por parte de los adolescentes infractores, volviéndose particularmente relevante por un lado, el rol del juez de garantía, en cuanto al control de la voluntariedad y, por el otro, el del defensor juvenil, en cuanto asesor de las decisiones procesales a las que debe arribar el adolescente infractor.

4.- A lo anterior es necesario agregar, que la ejecución de las sanciones no privativas de la libertad tienen asociadas un catálogo de garantías y derechos, junto con una regulación novedosa del quebramiento y el establecimiento de una serie de innovaciones en relación a la pena, como es la posibilidad de sustituirla, remitirla, suspenderla y combinarla. La desventaja que presentan dice relación con la inscripción en el registro de condenas y la apertura de un prontuario criminal, eso si, con las restricciones que la misma LRPA estableció.

5.- Considerando lo señalado, y entendiendo que el modelo penal al que aspiramos, es aquel respetuoso de las garantías del debido proceso, de la presunción de inocencia y el principio de culpabilidad, y entendiendo que el fin perseguido por ambos mecanismo es el mismo, parece razonable inclinarse por la utilización preferente de las sanciones no privativas de la libertad de reparación del daño y servicios en beneficio de la comunidad para la consecución de los fines propios establecidos en la Ley $\mathrm{N}^{\mathrm{o}} 20.084$ y la construcción de un modelo penal acorde a un Estado democrático de Derecho. Pero como se señaló en páginas anteriores, corresponderá a los operadores en definitiva dar solución a la constante tensión entre garantismo y eficiencia. En ese sentido el presente trabajo sólo pretende exponer las consecuencias de optar por una u otra vía. 